\title{
Integração das tecnologias educacionais em rede e convergência entre modalidades na UFSM
}

The integration of online educational technologies and convergence among modalities at UFSM

\author{
Elena Maria Mallmann', Fábio da Purificação de Bastos², Ricardo Simão Diniz Dalmolin³ \\ I Universidade Federal de Santa Maria, Professora-pesquisadora UAB/UFSM \\ 2 Universidade Federal de Santa Maria, Professor-pesquisador UAB/UFSM \\ 3 Universidade Federal de Santa Maria, Coordenador UAB/UFSM
}

\begin{abstract}
Resumo
O objetivo é analisar criticamente as ações desenvolvidas no âmbito do Núcleo de Tecnologias Educacionais para induzir a integração das tecnologias em rede e convergência entre modalidades na Universidade Federal de Santa Maria. Metologicamente, contemplamos as políticas e logística de pesquisa, desenvolvimento e capacitação viabilizadas por meio da: 1) estruturação de equipe multidisciplinar com foco em Ambientes Virtuais de Ensino-Aprendizagem, Recursos Educacionais e Atividades de Estudo; 2) realização de concursos públicos para professores adjuntos na área multidisciplinar em oito unidades de ensino; 3) institucionalização da plataforma Moodle como Apoio para o Ensino Presencial na Graduação, Pós-Graduação e Extensão; 4) interface acadêmica entre tecnologias Portal do Professor, Portal do Aluno e Moodle; 5) seleção de projetos de pesquisa para a Integração das Tecnologias de Informação e Comunicação (TIC) e Convergência das Modalidades Educacionais nos Cursos de Graduação (Edital público n. 07/2012). Analiticamente, a abordagem contempla parâmetros unificadores para todas as ações mencionadas: a) apresentação; b) situação-limite e c) viável-possível. Conclusivamente, sinalizamos que a integração das tecnologias em rede e convergência entre modalidades é uma prospecção política, viável-possível e inovadora-sustentável, para potencializar expansão e interiorização do ensino superior público e gratuito.
\end{abstract}

Palavras Chave: Tecnologia Educacional em Rede; Integração; Convergência; Modalidades educacionais

\begin{abstract}
The aim is to critically analyze the actions carried out under the Center for Educational Technologies to induce integration of network technologies and convergence between modalities at the Federal University of Santa Maria (UFSM). Methodologically contemplate the policies and logistics research, development and training made possible by: 1) structuring multidisciplinary team focused on Virtual Environments for Teaching - Learning, Educational Resources and Activities Study, 2) conducting contests for professors in multidisciplinary area in eight different units of the UFSM, and 3) institutionalization of Moodle as Support for Classroom teaching in Undergraduate, Graduate and Extension courses, 4) interface academic between technologies Teacher Portal, Student Portal and Moodle, 5) selection of research projects for the Integration of Information and Communication Technology (ICT) and convergence of modalities in Undergraduate Education (public Notice no. 07/2012). Analytically, the approach includes unifiers parameters for all actions mentioned: a) presentation b) limit situation c) viable - possible. Conclusively, we signaled that the integration of network technologies and convergence between modes is a prospecting policy, viable - possible and innovative - sustainable, to reach the expansion and to enhance internalization of free public higher education..
\end{abstract}

Keywords: Educational Technology Network; Integration; Convergence; educational Modalities 


\section{INTRODUÇÃO}

O propósito é explicitar avanços e desafios na implementação de políticas públicas locais e regionais, para induzir e fomentar a integração de tecnologias em rede e convergência entre modalidades educacionais. Destacamos que isso está previsto e regulamentado pela legislação educacional no escopo nacional.

Com a finalidade de implementar localmente as políticas públicas definidas pelas instâncias ministeriais e suas respectivas agências de fomento, a Universidade Federal de Santa Maria (UFSM), através do Núcleo de Tecnologia Educacional (NTE) abriga o Sistema Universidade Aberta do Brasil (UAB). O NTE atua como agente de inovação dos processos de ensino-aprendizagem, mediados por tecnologias em rede, fomentando institucionalmente a incorporação das Tecnologias de Informação e Comunicação aos Projetos Pedagógicos dos Cursos graduação, pós-graduação e extensão).

Desse modo, analisamos as ações políticas e logísticas de pesquisa, desenvolvimento e capacitação que vem sendo implementadas na UFSM, com destaque para as finalidades, competências e organização, que competem ao NTE na esfera das modalidades presencial, semipresencial e a distância.

Sinalizamos ao final que a integração das tecnologias em rede e convergência entre modalidades educacionais é uma prospecção política, viável-possível e inovadora-sustentável, para potencializar expansão e interiorização do ensino superior público e gratuito.

\section{I) EstruturaÇÃo de EQUIPE MULTIDISCIPLINAR: Ambiente Virtual de Ensino-Aprendizagem, Recursos Educacionais e Atividades de Estudo}

\section{I.I Apresentação}

O processo ensino-aprendizagem mediado por tecnologias educacionais em rede, tanto na modalidade presencial quanto a distância, intensifica o contexto de inovação na docência universitária multidisciplinar. Essa inovação é marcada, principalmente, pelo modo de produção multidisciplinar, atualmente de forma hipermidiática, no tripé ensino, pesquisa e extensão nas instituições universitárias (Mallmann, 2008).

Na UFSM, a equipe multidisciplinar da UAB atua no NTE (Figura 1), estruturando as atividades de pesquisa, desenvolvimento e capacitação em três frentes de trabalho coordenadas por professores-pesquisadores: Ambiente Virtual de Ensino-Aprendizagem, Recursos Educacionais e Atividades de Estudo. Essas três são integradas para catalisar a produção de recursos educacionais e atividades de estudo no Moodle, de forma indissociável em cada unidade didática, garantindo a implementação hipermidiática das ações docentes e discentes previstas no projeto pedagógico de curso.

O documento Referenciais de Qualidade para Educação Superior a Distância do Ministério da Educação, em consonância com o Decreto 5.622 , de 19 de dezembro de 2005, estabelece a equipe multidisciplinar entre as oito das dimensões fundamentais nas instituições, pois "qualquer que seja a opção estabelecida, os recursos humanos devem configurar uma equipe multidisciplinar com funções de planejamento, implementação e gestão dos cursos a distância, onde três categorias profissionais, que devem estar em constante qualificação, são essenciais para oferta de qualidade: • docentes; - tutores; • pessoal técnico-administrativo".

Nessa perspectiva, na UAB/UFSM investe-se na capacitação continuada anual, conforme orientação e financiamento da Diretoria de Educação a Distância (DED) da Capes, dos profissionais da equipe multidisciplinar (professores-pesquisadores, técnicos em informática, analistas de sistemas, webdesigners, técnicos em assuntos educacionais, estagiários de graduação, estudantes de pós-graduação). Isso porque que a preocupação

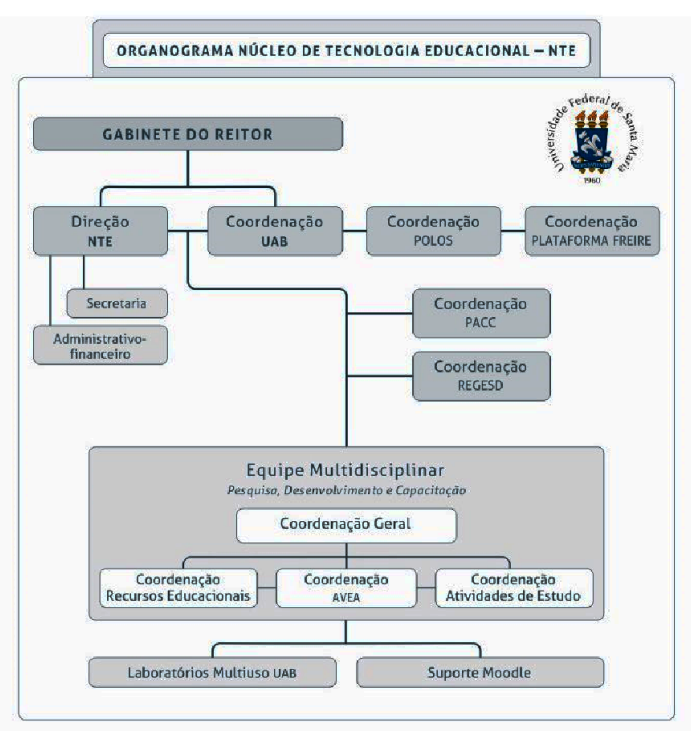

Figura 1: Estrutura da Equipe Multidisciplinar no NTE/UFSM 
central gira em torno da performance individual e colaborativa de cada um, para o alcance dos objetivos de ensino-aprendizagem dos cursos mediados, pedagógica e tecnologicamente em rede, especialmente as ferramentas de recursos e atividades hipermidiáticas do Moodle.

\section{I.2 Situação-limite}

A institucionalização das equipes multidisciplinares nas universidades brasileiras, por conta da implantação do Sistema UAB, ainda é limitada pela baixa compreensão do potencial hipermidiático da tecnologia educacional em rede (Moodle) que media a modalidade a distância dos cursos.

No escopo da modularidade do Moodle (suporte a objetos de variadas linguagens midiáticas), é viável-possível elevar os níveis hipermídia dos materiais didáticos (recursos e atividades) no âmbito das ferramentas de conteúdos (páginas web, sumários, rótulos, links à arquivos e sites, diretórios); comunicação e informação (notícias, calendários, mensagens, e-mail, chat, fóruns de perguntas e respostas); construcionistas (diários, lição tarefa, questionários); colaboração (wiki, glossário, laboratórios de avaliação, fóruns de discussão); investigação (pesquisas de avaliação, enquetes, múltipla escolha, surveys) (Mallmann e outros, 2012, p. 10).

Os diversos perfis e atribuições profissionais implicam em responsabilidades compartilhadas e funções multidisciplinares nos quefazeres pedagógicos mediados por tecnologias com potencial hipermídia como o Moodle. Por isso, a colaboração entre os pares é fundamental no âmbito do trabalho multidisciplinar para que se alcance em médio ou curto prazo o sucesso escolar desejado com a integração das tecnologias em rede e convergência entre modalidades.

Numa equipe multidisciplinar todos são responsáveis, em alguma instância, pelo movimento do processo ensino-aprendizagem, que transcorre em torno dos conteúdos curriculares de cada curso (organização conceitual e temas estruturadores) funcionando tecnologicamente no Moodle. As tarefas dos profissionais que integram a equipe multidisciplinar perpassam o planejamento didático-metodológico dos materiais didáticos hipermidiáticos, customização dos ambientes virtuais, desenvolvimento de atividades de estudo, sistemas de acompanhamento e tutoria.

Logo, a logística e infraestrutura acadêmica e tecnológica dos cursos na modalidade a distância requer trabalho multidisciplinar em rede. Como a indução e parametrização das políticas públicas de cada setor e contexto político-econômico-sócio-cultural ainda não é bem definido, principalmente pelo fato da UAB ser significativamente recente, o trabalho multidisciplinar fica multifacetado e muito fragmentado nas instituições.

\section{I.3 Viável-possível}

O par recursos e atividades de estudo (material didático hipermídia), no processo ensino-aprendizagem mediado por tecnologias em rede, requer fluxogramas de produção que envolvem profissionais de vários campos organizados em equipes multidisciplinares: pedagogia, tecnologia, webdesigner, línguas, gestão, entre outras. Logo, é essencial que a equipe multidisciplinar e professores-pesquisadores interajam entre si e desenvolvam interatividade no Moodle. Essa interação é basilar para compreender os códigos e operar com as tecnologias educacionais explorando todo potencial hipermídia das ferramentas síncronas e assíncronas (Tarouco e Ávila, 2007).

Nesse sentido, no NTE/UAB/UFSM avançamos na implementação de soluções que melhorem a fluência de professores, tutores, monitores e estudantes nas tecnologias educacionais em rede, explicitando suas naturezas abertas e livres (De Bastos e outros, 2013).

Dentre essas soluções, estão os cursos de capacitação continuada, suporte técnico síncrono (telefone) e assíncrono (e-mail), tutoriais (Biblioteca do NTE disponível em <http:// nte.ufsm.br/moodle/mod/resource/view. php?id=144046\&username $=$ guest $>$. Além disso, o destaque é para a disponibilização de exemplar de organização didático-metodológica de uma disciplina no Moodle (Figura 2). O acesso é aberto ao público para Nome de usuário: visitante - Senha: visitante (disponível em <http://serveredt.ctlab. ufsm.br/moodle22/login/index.php >).

A consolidação de projetos pedagógicos inovadores do ponto de vista dos conteúdos programáticos, perfil dos egressos, estratégias metodológicas, aderência às temáticas transversais, integralização e sequenciamento curricular aconselhado, infraestrutura compatível e dinâmicas de avaliação da aprendizagem, consolida esse modo de produção do ensino-aprendizagem. Modo este, essencialmente marcado pelo movimento interativo e flexível que as hipermídias educacionais em rede propiciam.

Portanto, o trabalho multidisciplinar em equipes pode otimizar de forma sustentável rotinas 


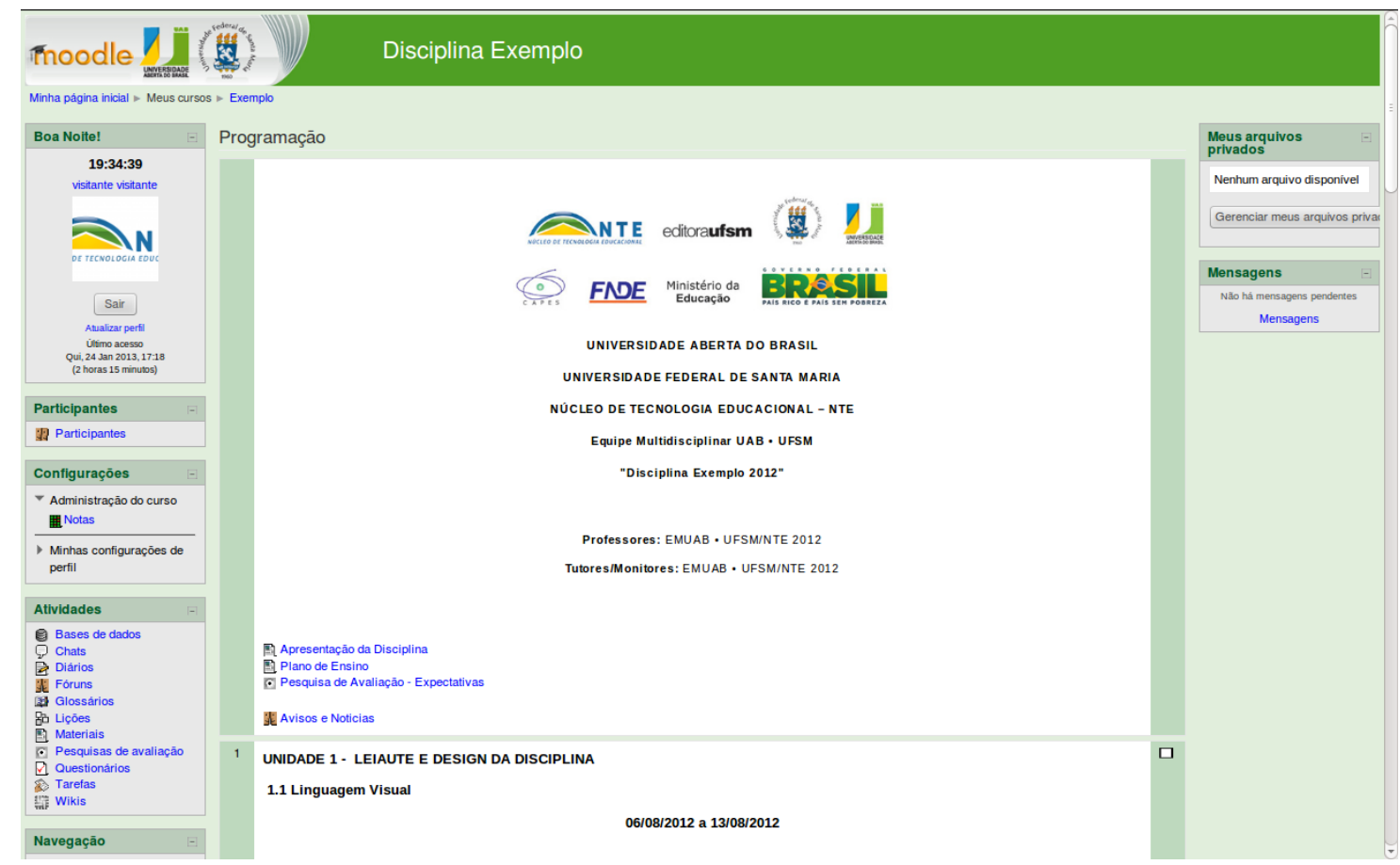

Figura 2: Disciplina-Exemplo no Moodle organizada pela Equipe Multidisciplinar da UAB/UFSM

colaborativas e potencializar práticas investigativas como diagnósticos da realidade concreta. Desta forma, teremos indicativos dos níveis de fluência nas tecnologias (Kafai e outros, 1999) mediadoras-chave dos estudantes, professores-pesquisadores, tutores, coordenadores e monitores.

\section{2) Realização de concursos públicos para PROFESSORES ADJUNTOS DOUTORES NA ÁREA MULTIDISCIPLINAR NAS UNIDADES DE ENSINO DA UFSM}

\section{I Apresentação}

A UFSM nunca antes na sua história realizou concurso público para docente com lotação nas unidades universitárias envolvidas com projetos de educação a distância, ou seja, nos centros de educação, ciências naturais e exatas, artes e letras, ciências rurais, ciências sociais e humanas e tecnologia. Além da formação básica na grande área das referidas unidades universitárias, exigiu-se formação em pós-graduação (mestrado e doutorado) multidisciplinar com ênfase em tecnologias da informação e comunicação.

Após a realização do concurso, os docentes aprovados foram cedidos pelas respectivas unidades universitárias ao gabinete do reitor para atuação no NTE da UFSM. A meta era induzir, no âmbito da
UFSM ao longo de três anos, ações educacionais mediadas por tecnologias em rede, em especial nos cursos de graduação na modalidade presencial.

Além disso, os respectivos docentes atuariam em projetos na modalidade educacional a distância, em especial na UAB, segundo a perspectiva didático-metodológico da equipe multidisciplinar. Dentre as frentes de atuação dos mesmos, podemos destacar a docência em Disciplinas Complementar de Graduação (DCG) nas referidas unidades universitárias, com foco na mediação tecnológico-educacional em rede (Moodle). Desta forma, os mesmos impactaram o ensino presencial de graduação no âmbito da integração das tecnologias em rede e convergência entre as modalidades educacionais.

\subsection{Situação-limite}

Embora todos os docentes tenham se inserido nos cursos de graduação das referidas unidades universitárias, isso ocorreu majoritariamente na instância curricular das disciplinas optativas, ou seja, das DCG. Dito de outra forma, a referida inserção não atingiu majoritariamente a esfera curricular obrigatória, básica ou específica, ficando restrita aos estudantes que fizeram esta opção na matrícula. Se por um lado, isso limita a indução 
empreendida pelo NTE, por outro, potencializa-a num número maior de cursos.

Outro aspecto que merece ser destacado é a baixa interação (Freire, 1996) entre estes docentes e os lotados nos departamentos que atuam em áreas e disciplinas específicas do conhecimento nas unidades universitárias. Talvez isso tenha motivado alguns deles a realizarem novos concursos públicos, desta vez em áreas do conhecimento específico, consequentemente, com lotação departamental. Consequentemente, embora a utilização do Moodle como apoio tenha crescido exponencialmente na modalidade presencial dos cursos de graduação e pós-graduação, isso não ocorreu na mesma perspectiva que os docentes multidisciplinares $o$ fazem.

Além disso, embora estes docentes cedidos para o NTE tenham tido uma produção científica multidisciplinar dentro do esperado, com destaque para a criação de um mestrado profissional em tecnologias educacionais em rede avaliado inicialmente pela Capes com conceito quatro, a integração dos docentes nas referidas unidades universitárias foi significativamente baixa.

\subsection{Viável-possível}

Por se tratar de uma iniciativa político-educacional pontual, tanto do ponto de vista temporal como do institucional, uma melhor solução pode ser obtida com uma cedência parcial ou associada ao projeto integrado no âmbito da unidade universitária. Dito de outra forma, é pre- ciso garantir a interação docente em ações desta natureza, para que a mesma não seja pontual, atingindo prioritariamente os discentes e minoritariamente os docentes.

Outra via pode ser a proposição de cursos de extensão e aperfeiçoamento na modalidade a distância de curta duração (variando entre um e dois semestres) nas unidades universitárias, coordenados prioritariamente por grupos de docentes com intencionalidade e performance multidisciplinar. Em outras palavras, cursos temáticos de curta duração e a distância, mediados por tecnologias educacionais em rede, poderiam impactar os de longa duração e presencial, como os de graduação presencial, em média de oito semestres.

\section{3) Institucionalização da plataforma Moodle como Apoio para o Ensino Presencial}

\section{I Apresentação}

A ideia de institucionalizar uma tecnologia educacional em rede, livre e aberta, já customizada e utilizada na modalidade educacional no âmbito da UAB, para a modalidade presencial nos cursos de extensão, graduação e pós-graduação na UFSM (Figura 3).

Embora seja inédita na mesma, já é realidade na maioria das instituições públicas de ensino superior que integram o sistema UAB (UFRGS e UFSC, por exemplo). O maior benefício educacional é a potencialidade da integração da cultura

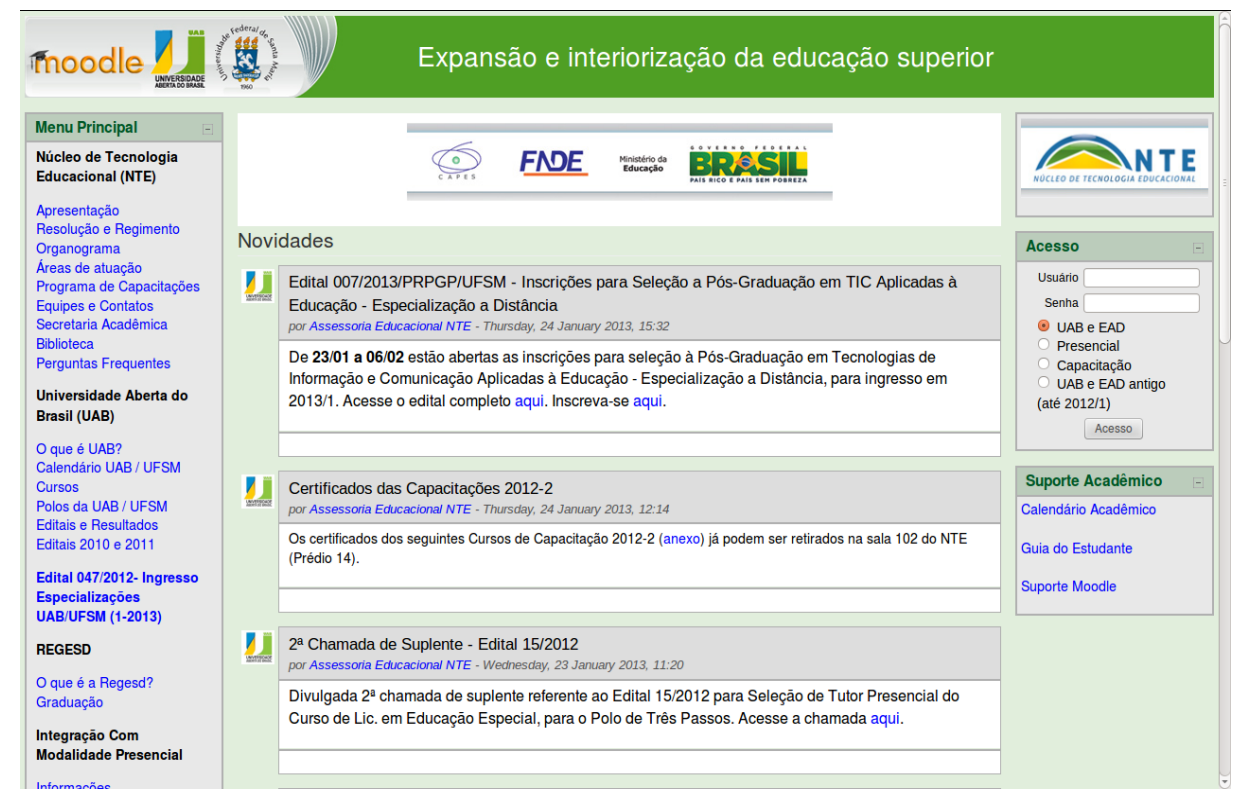

Figura 3: Portal do NTE - acesso ao Moodle UAB/EaD; Presencial e Capacitação. 
digital-virtual no escopo dos recursos educacionais que mediam os cursos na modalidade presencial, alguns ainda predominantemente mediados pelo impresso copiado ilegalmente e desconectados da produção científico-tecnológica publicizada na internet.

Talvez em função disso, muitos docentes da UFSM se candidataram aos cursos de capacitação continuada anual oferecidos pelo NTE, com financiamento da Diretoria de Educação a Distância da Capes, em especial o tematizado pela tecnologia educacional em rede Moodle. Isso pode ser um sinalizador que o Moodle está sendo utilizado nos mais diferentes cursos, para além de repositório de conteúdos digitais-virtuais, organizando didático-metodologicamente as unidades e módulos temáticos disciplinares dos cursos presenciais de graduação, extensão e pós-graduação.

\subsection{Situação-limite}

Inicialmente os docentes interessados em utilizar o Moodle como apoio nas disciplinas presenciais dos cursos de graduação, pós-graduação e extensão, necessitavam solicitar tal demanda via e-mail ao NTE. Isso gerava claramente uma dependência tecnológica no fazer docente, além de publicizar sua opção pela mediação tecnológica em rede.

Atualmente a interface entre Portal do Professor da UFSM e o Moodle presencial permite ao docente realizar esta tarefa sem o auxílio do NTE, embora o suporte tecnológico seja oferecido para aqueles que solicitarem.

Isso, por um lado, aumentou exponencialmente o número de docentes e, consequentemente, de disciplinas mediadas por esta tecnologia educacional em rede. Por outro lado, a utilização maciça como repositório é fato institucional. Não que isso seja limitador de ações docentes efetivamente mediadas pelo Moodle, mas o trabalho orientador na perspectiva de boas práticas em rede fica mais difícil e volumoso, em especial no âmbito da equipe multidisciplinar.

\subsection{Viável-possível}

A criação e disponibilização de Disciplina-Exemplo para todos, no âmbito da UFSM (disponível em http://serveredt.ctlab.ufsm.br/moodle22/ login/index.php )pela equipe multidisciplinar da UAB, é uma possível solução de capacitação docente na perspectiva MOOC (conceituação disponível em http://en.wikipedia.org/wiki/Massive_open_online_course ). A meta é explicitar, como as ferramentas de recursos e atividades do
Moodle, podem organizar as unidades didáticas das disciplinas dos cursos de graduação, pós-graduação e extensão ao longo do calendário letivo.

Como força-tarefa guiada por esta orientação didático-metodológica (Disciplina-Exemplo no Moodle), o NTE pretende mudar o nível da fluência dos docentes da UFSM, inovando nos cursos de graduação, extensão e pós-graduação, na perspectiva da integração das tecnologias de informação e comunicação e convergência entre as modalidades educacionais. Seja no âmbito da capacitação anual continuada da Capes, seja na produção de material didático hipermidiático, o NTE concentrará esforços para que a prática docente seja mediada tecnologicamente em rede no Moodle na perspectiva aberta e livre.

\section{4) Interface entre tecnologias em rede Portal do Professor, Portal do Aluno e Moodle}

\section{I Apresentação}

Do ponto de vista institucional é essencial que a integração das tecnologias em rede e a convergência entre as modalidades educacionais, seja catalisada por ferramentas de gestão discente, docente e técnico-administrativa na internet. $\mathrm{Na}$ UFSM a referida catálise é mediada pelos portais do Professor, Aluno e Servidor. No âmbito do ensino-aprendizagem especificamente, o Moodle é acessado através de links nos dois primeiros.

Contudo, até março de 2012 esta integração dependia, conforme mencionado anteriormente, de solicitação docente ao NTE, ficando a mesma dependente da força de trabalho do corpo técnico da equipe multidisciplinar da UAB. Atualmente o CPD implementou, com a orientação do NTE, interface gráfico no portal do Professor da UFSM (http://portal.ufsm.br/professor/login.jsp) para que a integração da tecnologia educacional em rede Moodle possa potencializar a convergência entre as modalidades educacionais nos cursos de graduação, extensão e pós-graduação.

\subsection{Situação-limite}

$\mathrm{Na}$ maioria das vezes em que ocorrem problemas nesta interface tanto docentes como discentes os atribuem ao Moodle, principalmente pela cultura de que tudo que é livre e aberto é de baixa qualidade tecnológica. $\mathrm{Na}$ prática, o problema ocorre no SIE, que é a tecnologia-chave responsável pela organização acadêmica na UFSM. Nela estão armazenados dados que o Moodle necessita importar e exportar para os portais do 
professor e aluno.

Além disso, por ser uma tecnologia mais antiga e proprietária, problemas no SIE necessitam sempre de mais hora-homem para solução, deixando inoperante o processo ensino-aprendizagem mediado em rede pelo Moodle. Quando isso ocorre, o NTE imediatamente informa aos discentes e docentes para que tenham paciência histórica, própria daqueles que estão na esfera da cognoscência. Se necessário for, solicitamos que prazos de atividades de estudo sejam dilatados, sempre atendendo o esquadrinhamento do tempo didático dos calendários institucionais.

\subsection{Viável-possível}

Atualmente CPD e NTE trabalham para integrar o sistema de avaliação na graduação e pós-graduação nos portais do professor, aluno e Moodle. Dito de outra forma, possibilitar a exportação pelo Moodle do conjunto semestral de avaliação discente para os portais do Professor e Aluno e, consequentemente para o SIE, diminuiria drasticamente o retrabalho docente realizado no portal do professor, feito equivocadamente do ponto de vista pedagógico, sempre ao final do semestre letivo. Convém ressaltar que na modalidade presencial, tanto atividades de estudo a distância como avaliações presenciais, podem ser realizadas no Moodle sob monitoramento docente.

Além disso, pretendemos viabilizar, ainda ao longo do ano de 2013, que o diário de classe em rede do Portal do Professor possa ser exportado dos módulos didáticos-metodológicos do Moodle. Com a orientação que o NTE está fornecendo através da proposição da Disciplina-Exemplo, os docentes poderão organizar suas dezessete semanas semestrais e ao final da implementação, como o fazem no início com a importação da turma discente no portal do professor da UFSM, apenas exportar o conteúdo didático das aulas para o diário já existente.

\section{5) Edital público (N. 07/20 I 2) para seleçÃo de PROJETOS PARA A INTEGRAÇÃo dAS TECNOLOGIAS DE INFORMAÇÃ̃o E CoMUNiCAÇÃo (TIC) E Convergência das Modalidades Educacionais nos Cursos de Graduação - UFSM 20I2/I.}

\section{I Apresentação}

Tendo em vista a atuação do NTE como agente catalisador de inovação nos processos de ensino-aprendizagem mediados por tecnologias em rede, em 2012 inovamos na UFSM com a elaboração, publicação e implementação do edital público $\mathrm{n}^{\circ} 07 / 2012$. O mesmo tinha como propósito fomentar a integração institucional das Tecnologias de Informação e Comunicação aos Projetos Pedagógicos dos Cursos graduação, pós-graduação e extensão e convergência entre modalidades.

Como estratégia acoplada à iniciativa anterior da DED/Capes, lançamos o Edital Público NTE n. 07/2012 em parceria com a Pró-Reitoria de Graduação, com a finalidade explícita de atingir a formação inicial dos estudantes da UFSM. Os objetivos do referido edital eram: a) incentivar a utilização do Ambiente Virtual de Ensino-Aprendizagem (Moodle) em 50 (cinquenta) disciplinas de cursos de Graduação da UFSM e b) proporcionar conhecimento e apropriação de formas de ensinar/ aprender em rede, flexibilizando e diversificando o processo com opções de recursos e atividades educacionais aos estudantes.

Cada projeto contemplado fez jus a um recurso financeiro de $\mathrm{R} \$ 1.600,00$ referente ao pagamento de bolsas de monitoria para estudantes de graduação ou pós-graduação. Na prática, o que fizemos foi fomentar com bolsa o trabalho de tutoria, no âmbito presencial denominado de monitoria, para os estudantes de graduação auxiliarem os docentes no trabalho de integração do Moodle nas aulas.

\subsection{Situação-limite}

O Edital NTE n. 07/2012 previa como disposição preliminar que os projetos poderiam ser propostos por docentes responsáveis por disciplinas dos cursos de Graduação da UFSM, para utilização de vinte por cento $(20 \%)$ da carga horária além do total, conforme portaria ministerial $\mathrm{n}^{\circ} 4059$, de 10 de dezembro de 2004 (DOU de 13/12/2004, Seção 1, p. 34).

Isso explicita que todas as estratégias de inovação do NTE estão coerentes com a legislação educacional, mas é uma evidência de alerta na instituição, visto que muitos projetos pedagógicos ainda não contemplam efetivamente a possibilidade de integração efetiva das tecnologias em rede para realização de vinte por cento de atividades a distância.

Embora tenhamos contemplado as 50 vagas oferecidas no edital, a elaboração de um projeto estruturado com preocupação temática, justificativa, metodologia, resultados esperados e cronograma gerou demanda de dúvidas e orientações para a equipe multidisciplinar.

Para nós, isso demonstra claramente que 
nem sempre as atividades de ensino nos cursos de graduação estão efetivamente acopladas às atividades de pesquisa, gerando diagnósticos para melhoria das práticas docentes e discentes. A aposta é que a integração de tecnologias como o Moodle, que possui ferramentas de Pesquisa de Avaliação tipo survey, impulsione condições para implementação de práticas de ensino-aprendizagem mais investigativas na UFSM.

\subsection{Viável-possível}

A proposição do Edital NTE n. 07/2012 esteve integrado ao plano de atividades previsto do projeto de pesquisa "Performance Docente em Tecnologias Educacionais Hipermídia: integração e convergência". O mesmo foi aprovado e registrado internamente por comissão de Ensino, Pesquisa e Extensão (Cepex) e conta com financiamento externo proveniente do Edital PqG Fapergs/2011 (Mallmann, 2011). Com o referido recurso foi possível a aquisição de equipamento Storage para suportar e gerenciar armazenamento de dados oriundos da institucionalização do Moodle como
Apoio para o Ensino Presencial. As ações de inovação do NTE, portanto, precisam cada vez mais estar acopladas tanto às demandas de ensino, pesquisa e extensão internas quanto à dinâmica para geração de inovações científico-tecnológicas geradas pelas agências de fomento do país.

Além disso, é preciso priorizar a melhoria dos índices de fluência tecnológica no Moodle, com a implementação de cursos de capacitação, talvez através de MOOC (Massive Open Online Courses), tanto para docentes quanto para estudantes (com potencial de monitores) envolvidos em projetos de pesquisa em ensino nas mais diferentes áreas do conhecimento.

Nos cursos de capacitação programamos materiais didáticos (recursos e atividades) organizados didaticamente em quatro módulos: a) integração das tecnologias educacionais e convergência entre modalidades; b) tecnologia educacional Moodle; c) recursos educacionais; d) atividades de estudo, os quais já disponibilizamos no link biblioteca do NTE (Figura 4).

Em cada curso realizamos encontros presenciais, atividades nas diversas ferramentas

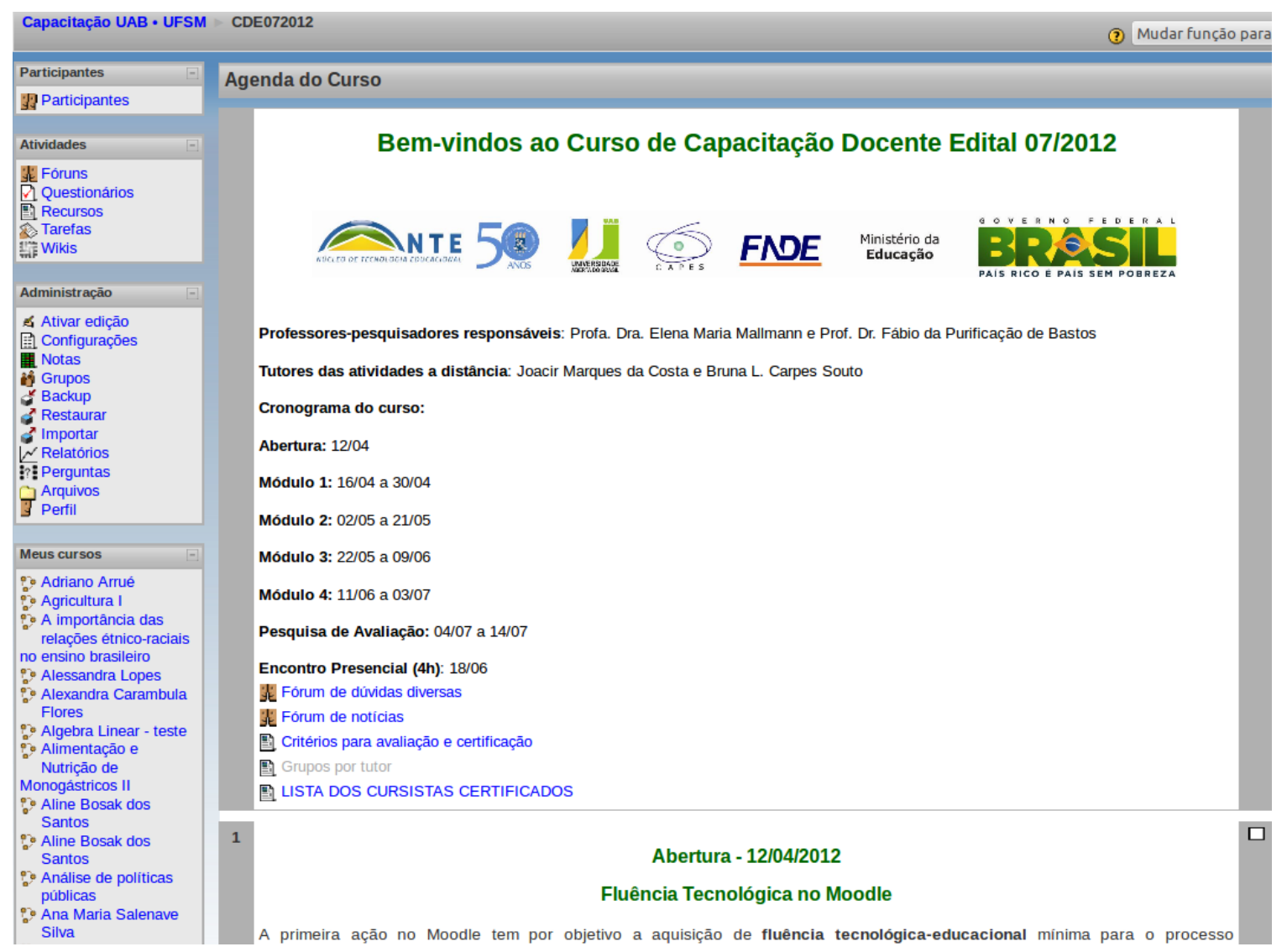

Figura 4: Exemplar de curso de capacitação de professores desenvolvido pelo NTE. 
do Moodle, criação de recursos em disciplinas com perfil de edição, além do monitoramento e orientação específicos realizados pelos docentes e tutores (estudantes de pós-graduação) responsáveis e atuantes na equipe multidisciplinar do NTE.

\section{Conclusão}

O intuito de explicitar a política educacional da UFSM, no escopo das ações inovadoras viáveis-possíveis que competem ao NTE para fomentar a integração das tecnologias educacionais em rede e convergência entre modalidades, pode não ter sido bem sucedida principalmente porque é parca a produção científica sobre isso no país.

Contudo, esperamos ter deixado claro que o destaque é o acoplamento entre pesquisa, desenvolvimento e capacitação, necessariamente viabilizado por meio de:

1) estruturação de equipe multidisciplinar com foco em Ambientes Virtuais de Ensino-Aprendizagem, Recursos Educacionais e Atividades de Estudo;

2) realização de concursos públicos docente na área multidisciplinar em unidades de ensino aos invés de departamentos;

3) institucionalização de tecnologia educacional em rede livre e aberta como apoio para o ensino presencial na graduação, pós-graduação e extensão;

4) interface acadêmica entre tecnologias Portal do Professor, Portal do Aluno, Moodle e Sistema Acadêmico informatizado;

5) seleção de projetos de pesquisa para a Integração das Tecnologias de Informação e Comunicação (TIC) e Convergência das Modalidades Educacionais nos Cursos de Graduação (Edital público n. 07/2012).

As ações implementadas de modo multidisciplinar na UFSM com o suporte oferecido pelo NTE estão na perspectiva da prática da liberdade mediada por tecnologias em rede, pois estão em conformidade com:

a) a normatização institucional (calendário acadêmico; guia do estudante);

b) tecnologia educacional (desenvolvimento, atualização e customização do Moodle para graduação, pós-graduação e extensão);

c) as características da interatividade, não linearidade, velocidade de acesso, flexibilidade cognitiva típicas da hipermídia (tutoriais do professor e do aluno, tutoriais de ferramentas colaborativas, materiais didáticos das capacitações) e d) resultados de pesquisa e demandas capacitação (recursos, atividades a distância, fluxogramas de produção, guia de tutores).

Na UFSM, o esforço da equipe multidisciplinar da UAB no NTE é contínuo para que melhores índices de interatividade, interação, autonomia e produção colaborativa (autoria e coautoria), sejam alcançados por todos que utilizam as tecnologias em rede para mediar ensino, pesquisa e extensão. Acreditamos que desse modo podemos produzir inovação conceitual e didático-metodológica no âmbito da expansão do ensino superior público no Brasil.

Efetivamente, as ações de pesquisa, desenvolvimento e capacitação precisam melhorar a fluência na performance hipermidiática em rede de todos os integrantes, promovendo integração das tecnologias e convergência entre modalidades. Fluência é basilar para suscitar movimentos contínuos de avaliação (retrospecção) das ações implementadas e, ao mesmo tempo, gerar novos programas (prospecção viável-possível).

Em cada uma dessas cinco ações analisamos as situações-limite e potencial inovador, tendo em vista que a integração das tecnologias, embora tenha caráter acentuado na UAB visto a amplitude de cursos oferecidos, não se restringe a uma modalidade educacional. Mais do que isso, perpassa por iniciativas e atividades de caráter permanente locadas no tripé educativo superior do ensino, da pesquisa e da extensão.

A análise dessas ações inovadoras no âmbito interno da UFSM, esboçada ao longo deste texto, em especial nos itens situação-limite e viáveis-possíveis, permite ressaltar o avanço necessário na fluência tecnológico-educacional em rede por todos os constituintes dos sistemas de ensino superior público. Acreditamos que, assim, estaremos em consonância com as metas das políticas públicas de expansão e interiorização do ensino na esfera do crescimento sócio-econômico gerador de desenvolvimento sócio-cultural e eliminação da pobreza no país.

\section{ReferênCIAs Bibliográficas}

Brasil. MEC. Decreto 5.622 de 19de dezembro de 2005. Disponível em: < http://www.uab.capes.gov.br/images/stories/downloads/legislacao/decreto5622.pdf $>$. style="color: \#000000;">Acesso em: 08 janeiro de 2013. 
Brasil. MEC. Referenciais de Qualidade para Educação Superior a Distância do Ministério da Educação. Disponível em: < http://portal.mec.gov.br/index. php?option $=$ com_content $\&$ view $=$ article $\& i d=12777 \% 3 \mathrm{~A}$ referenciais-de-qualidade-para-ead $\&$ catid $=193 \% 3$ Aseed-educacao-a-distancia\&Itemid=865\&gt; . Acesso em: 08 janeiro de 2013.

DE BASTOS, F. da P. e outros. Universidade Aberta do Brasil Mediada por Software Livre. 2013 (no prelo).

FREIRE, Paulo. Pedagogia da Autonomia: Saberes necessários à prática educativa. São Paulo: Paz e Terra, 1996.

KAFAI, Y. e outros. Being Fluent with Information Technology, 1999. Disponível em: <http://www.nap. edu/catalog/6482.html\&gt\&gt> . Acesso em: 21 de janeiro de 2013.

MALLMANN, Elena Maria. Mediação pedagógica em educação a distância: cartografia da performance docente no processo de elaboração de materiais didáticos. Tese de doutorado. Florianópolis: UFSC/CED/ PPGE, 2008.

MALLMANN, Elena Maria. Performance Docente em Tecnologias Educacionais Hipermídia: integração e convergência. Projeto financiado Edital PqG Fapergs/2011, Santa Maria, 2011.

MALLMANN, Elena Maria e outros. Potencial da Página Web do Moodle para Produção de Recursos Educacionais Hipermídia. In: Anais 18o. Congresso Internacional $\mathrm{ABED}$ de Educação a Distância. São Luís/MA, 2012.

TAROUCO, L. M. R; ÁVILA, B.; Multimídia na alfabetização digital com fluência para a autoria. In: Revista Novas Tecnologias na Educação - Renote. Vol.05, no. 2, 2007. Disponível em: < http://www. cinted.ufrgs.br/ciclo10/artigos/1Liane.pdf $>$ Acesso em 23 de janeiro de 2013.

Universidade Aberta do Brasil (UAB). Portal UAB. Disponível em: <http://www.uab.capes.gov.br/\&gt;. Acesso em: 08 de janeiro de 2013.

Universidade Federal de Santa Maria. Núcleo de Tecnologias Educacionais. Resolução n. 21/2011. Cria, na estrutura organizacional do Gabinete do Reitor, o Núcleo de Tecnologia Educacional - NTE, aprova o seu Regimento Interno e dá outras providências. Disponível em: < http://cead.ufsm.br/moodle/file. $\mathrm{php} / 1 /$ nte/resolucao_regimento.pdf $>$ Acesso em: 08 janeiro de 2013.

Moodle. Disponível em: <https://moodle.org/\&gt> Acesso em: 11 de janeiro de 2013.

Moodle Institucional na UFSM. Disponível em: <http:// nte.ufsm.br/moodle/\&gt>. Acesso em: 11 de janeiro de 2013.

Moodle Institucional na UFRGS. Disponível em: $<$ https://moodleinstitucional.ufrgs.br/login/index. php\&gt >. Acesso em: 11 de janeiro de 2013.

Moodle Institucional na UFSC. Disponível em: <https:// moodle.ufsc.br/\&gt>. Acesso em: 11 de janeiro de 2013. 